\title{
GEOLOGIA APLICADA À GESTÃO E PLANEJAMENTO URBANO - ANÁLISE DE MULTICRITÉRIO DA PORÇÃO SUL DA MANCHA URBANA DE NOVA LIMA E HONÓRIO BICALHO
}

\author{
Carlos V. H. M. Oliveira ${ }^{1}$, Pedro A. M. B. Gonçalves ${ }^{1}$, Danilo M. Magalhães ${ }^{1}$
}

${ }^{1}$ Instituto de Engenharia e Tecnologia, Centro Universitário de Belo Horizonte, Campus Estoril - Av. Professor Mário Werneck, 1685, Buritis, 30575-180, Belo Horizonte - MG (carlosvhmo@hotmail.com; autor correspondente)

Recebido em 20 de maio de 2019, aceito em 07 novembro de 2019

Resumo: Este estudo visa mostrar a aplicação da geologia em áreas urbanizadas para resolução de problemas geoambientais decorrentes da interação do homem com o meio físico. Muitas vezes estes problemas são ocasionados pela falta de planejamento governamental e conhecimento da sociedade acerca de fatores geológicos, morfológicos, hidrológicos, e suas implicações na gestão e planejamento urbano. E são exatamente estas causas que conduzem as pessoas a uma situação de vulnerabilidade. Para alcançar os objetivos deste trabalho, procurou-se aplicar uma análise multicriterial, que consiste em uma metodologia de Geoprocessamento que permite realizar análises de síntese por meio da combinação de diversas variáveis. Utiliza-se, para tanto, o exemplo do crescimento urbano na porção sul da cidade de Nova Lima e região de Honório Bicalho, segundo o eixo de expansão urbana na rodovia MG-030. Os resultados indicam áreas com susceptibilidade e vulnerabilidade relacionada a movimentos gravitacionais de massa, a partir das variáveis mensuradas no modelo. Os mapas temáticos gerados podem auxiliar na tomada de decisões no que tange à ocupação antrópica de áreas de risco e, dessa forma, contribuir com uma interação adequada entre expansão urbana e espaço físico.

Palavras-Chave: Geologia Urbana. Geoprocessamento. Análise de Multicritério. Risco Geológico. Tomada de decisões.

Abstract: This paper shows the applied geology in urban areas, for geoenvironmental issues within human interaction with the physical environment. Those issues occur due to the lack of people knowledge and government planning about geological, morphological and hydrological features and their implication, putting those people into a vulnerability status. At this matter a Geoprocessing methodology of multicriteria analysis was used, allowing to synthesis results combined with many aspects. As an example were analyzed the urban expansion axis in the MG-30 highway between the south of Nova Lima city and Honório Bicalho district. Results indicate areas with susceptibility and vulnerability to risk of mass wasting due to the variables used in the modeling. The theme maps generated has the objective to support decision-making of the problems involved, for planning and mitigate risk inherent of the terrain, allowing an adequate interaction between urban expansion and physical environment.

Keywords: Urban Geology. Geoprocessing. Multicriteria Analysis. Geological Risk. Decision-making.

\section{INTRODUCÃO}

A complexidade dos componentes geológicos e geomorfológicos, associada às intervenções antrópicas, tem contribuído intensamente para o surgimento de problemas que relacionam o ser humano ao território que o circunda, denominado problemas geoambientais (GOMES \& PEREIRA, 2014). A geologia, quando aplicada ao planejamento urbano, pode ser considerada como a gestora dos riscos de origem geológica (como movimentos de gravitacionais de massa) que afetam as pessoas e suas instituições, à medida que interagem com seu ambiente construído e natural, buscando melhorar a qualidade de vida dentro dos limites dos recursos disponíveis (CULSHAW \& PRINCE, 2013).

Para Parizi (2014) e Cerri \& Amaral (1985) o risco é dado pela possibilidade de um processo geológico ou fenômeno seja acompanhado de danos ou perdas. Junto ao risco estão associadas as terminologias de sucessitibilidade, que é inerente ao território e a possibilidade da ocorrência de um fenômeno; e vulnerabilidade, que Parizi $(2014$, p.1) define como: "o grau de perda de um dado elemento ou grupo de risco dentro de uma área afetada por um processo".

Em meio a essa temática, é essencial tratarmos o que é a cidade, do ponto de vista geológico, e como a geologia é importante para o desenvolvimento da mesma.

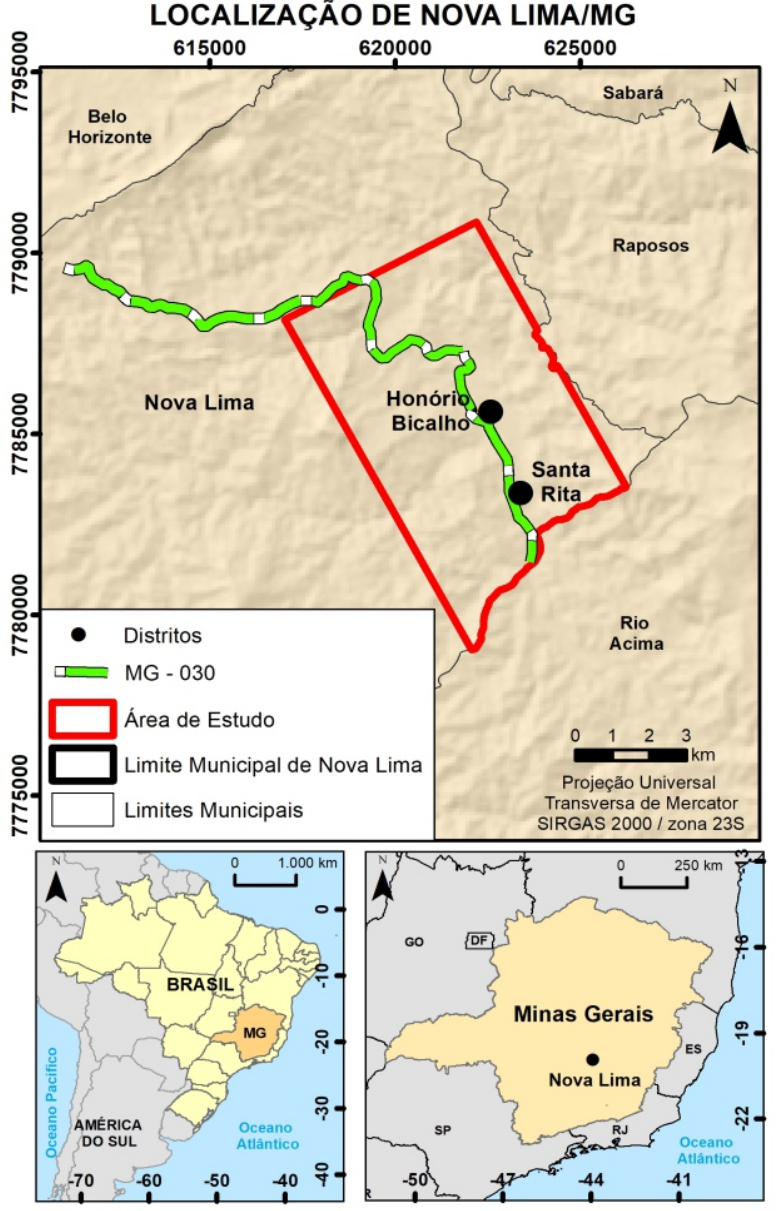

Figura 1-Localização da área em estudo. 
Na concepção de Carvalho (2001, p.11), "cidade é um constructo complexo" definido por três camadas: a camada da Superestrutura que reúne as estruturas antrópicas (moradia, indústria, áreas de lazer, entre outros); a Mesoestrutura, que tem por função propiciar condições de funcionamento das Superestruturas (sistema viário, hídrico, de saneamento, entre outros, adaptando-se ao porte e necessidades desta e às condições de suporte da camada abaixo) e por fim, a Infraestrutura, que é o sistema geológico por si só, tendo por função suprir e suportar a Super e Mesoestruturas. É, portanto, "tudo aquilo que sobre o qual se constrói alguma coisa” (CARVALHO, 2001, p.20).

A partir deste conceito, percebe-se a importância e aplicabilidade dos conhecimentos geológicos ao planejamento territorial e para a solução de problemas geoambientais. Neste âmbito, pode-se destacar os trabalhos relacionados à Geologia Urbana e à Geologia Ambiental que visam aplicar os conhecimentos geológicos para a resolução de problemas ambientais decorrentes da interação entre o homem e o meio físico (KELLER, 2011; UNESP, 2017).

Trata-se, especificamente, de aplicar a informação para resolver conflitos, ampliando a compreensão das dinâmicas territoriais e, segundo Moura et al. (2011, p.1), "caracterizar a realidade vigente e de predição de algumas condições latentes", seja do ambiente natural ou modificado. (KELLER, 2011; UNESP, 2017; MOURA et al., 2011).

Logo, a Geologia, por estudar a Terra e seus aspectos, como a superfície da crosta, é uma grande provedora de informações acerca das condições da infraestrutura (estrutura geológica) e deveria ser parte essencial do planejamento físico de todas as cidades, principalmente no que tange à previsão e antecipação de decisões pertinentes ao desenvolvimento frente ao crescimento dos centros urbanos, (LEGGET, 1969; LEGGET, 1973; SOUZA, 2004).

Visto o grande número de aspectos e informações que devem ser consideradas na avaliação do meio físico em interação com o meio urbano, sejam sociais, políticos, ambientais, dentre outros, ferramentas e metodologias de Geoprocessamento vêm sendo utilizadas para caracterização, análise e construção de cenários preditivos sobre o meio estudado. Câmara et al. (2001) informam que metodologias de geoprocessamento permitem armazenar, representar e processar as informações espaciais, através de técnicas matemáticas e computacionais, em ambiente virtual.

O geoprocessamento utiliza ferramentas disponíveis nos Sistemas de Informações Geográficas (SIG), que pode ser entendido como um sistema integrador de programas, equipamentos, metodologias, dados e pessoas ou usuários de forma que sejam possíveis a coleta, o armazenamento, o processamento, a análise e a produção de informações a partir de dados georreferenciados (TEIXEIRA et al., 1995).

Tais informações servem também como um sistema de apoio para tomada de decisões em um ambiente de resolução de problemas (COWEN, 1988).

Dentre as metodologias de análise espacial, apoiadas por recursos de geoprocessamento, dar-se-á ênfase, neste estudo, a Análise de Multicritérios (AM) de peso por evidência, pois permite a integração de diferentes planos de informação para geração de uma análise de síntese (ROCHA et al., 2018). A AM é descrita por Moura (2007) como uma metodologia de cruzamento de dados, conhecida também como árvore de decisões ou análise hierárquica de pesos, utilizando o emprego da média ponderada, portanto, a síntese das variáveis deve totalizar $100 \%$. Para a realização de uma análise de multicritérios é importante se ter em mente que os resultados representam uma situação em espaço, tempo e critérios específicos que são definidos pelos pesquisadores. Xavier-da-Silva (1999, p. 2), explica que tal análise parte dos pressupostos:

Todo fenômeno é passível de ser localizado; todo fenômeno tem sua extensão determinável; todo fenômeno está em constante alteração; todo fenômeno apresenta-se com relacionamentos, não sendo registrável qualquer fenômeno totalmente isolado.

Dessa maneira pode-se aplicar a AM com auxílio do SIG, pois os problemas de planejamento e gerenciamento do mundo real podem se beneficiar da combinação de suas técnicas e procedimentos (ZAMBON, 2005).

Partindo do exposto, o objetivo deste estudo é identificar áreas com maior suscetibilidade a movimentos gravitacionais por meio do cruzamento de variáveis sobre o meio físico. Especificamente, busca-se entender quais são as variáveis que condicionam a ocorrência de movimentos gravitacionais de massa na área de estudo a fim de gerar subsídio para o planejamento urbano a partir do entendimento das características do meio físico que possibilitam, ou não, as ocupações antrópicas.

\section{CONTEXTUALIZAÇÃO DAÁREA}

A área em estudo (Figura 1), se localiza na porção sul da área urbana da sede municipal de Nova Lima-MG e contempla, também, os distritos de Honório Bicalho e Santa Rita. Estes constituem um eixo importante de crescimento urbano, ao longo da rodovia MG-030, tendendo, com o tempo, a se conurbarem.

Segundo PNL (2020), desde a sua fundação, com a chegada do bandeirante paulista Domingos Rodrigues da Fonseca Leme em busca do ouro no século XVII, a cidade se caracteriza como uma forte economia voltada para indústria de bens de commodites, como o ouro e ferro, e seu crescimento econômico está diretamente ligado a estas atividades (PNL, 2020). Além da mineração, o município apresenta, também, uma dinâmica de ocupação territorial caracterizada por formação de condomínios de alto padrão de moradia, atendendo a uma demanda que é observada no eixo sul da Região Metropolitana de Belo Horizonte (RMBH).

A área em estudo se encontra no contexto geológico geotectônico do Quadrilátero Ferrífero (QF), inserido na porção sul do Cráton do São Francisco. 


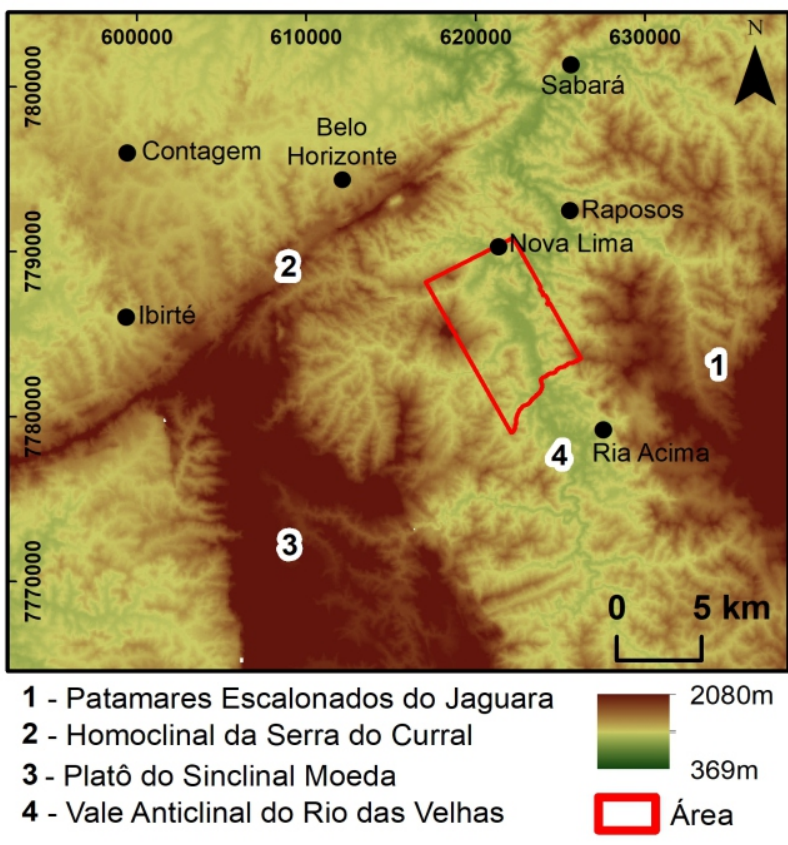

Figura 2-Caracterização morfoestrutural regional.

De forma mais especifica o município de Nova Lima se apresenta na junção do Homoclinal da Serra do Curral com a Serra da Moeda (Figura 2) (Alkmim \& Marshak, 1998).

Estratigraficamente se insere na sequência Arquena de rochas metavulcânicas sedimentar do Super Grupo Rio das Velhas (SGRV), sobreposta do Embasamento Cristalino do QF, descritos assim por Dorr (1969) e Alkmim \& Marshak (1998).

A lito-estratigrafia, como dito, pertencente ao SGRV corresponde, da mais antiga para a mais nova (Figura 3) pelo Grupo Nova Lima, de forma indivisa, contendo xistos de coloração verde e filitos com formações ferríferas (FF) subordinadas; sobrepondo esta, se encontra a Unidade Ouro Fino composta de rochas máficas-ultramáficas como metabassalto, metaperidotito e metatuffo básico, ocorrendo de forma subordinada metachert, formações ferríferas, xistos e quartzitos (Alkmim \& Marshak 1998);

A Unidade Morro Vermelho apresenta rochas Vulcano sedimentar-química na forma de metabasalto com formações ferríferas, metachert, xisto epiclástico e metavulcânica félsica. Unidade Mestre Caetano contendo sericita-clorita-quartzo xisto, sericita-clorita xisto, sericita xisto e xisto carbonoso, de forma subordinada Formações ferríferas e lapa seca. Acima destas, a Unidade Córrego do Sitio que compreende rochas ressedimentadas como metapelitos e metapsamitos de corrente de turbidez, subordinadamente xistos e formações ferríferas (Alkmim $\&$ Marshak 1998). Por último, as coberturas fanerozoicas compreendendo o aluvião, composto por areia, argila e cascalho, e o coluvião, composto por blocos, matacões e seixos de quartzito, itabirito e canga (DORR, 1969; LOBATO, 2005).

Segundo Pimentel et al. (2005) do programa APASUL
(Área de Proteção Ambiental do Sul) da região metropolitana de Belo Horizonte, os tipos de rochas encontrados influenciam diretamente na ocorrência de movimentos de massa, por exemplo depósitos aluviares, ocorrendo ao longo de drenagens, e as unidades coluvionares, capeando vertentes, apresentam baixa capacidade de suporte à ocupação com elevada suscetibilidade a erosão. As unidades compostas por rochas ultra básicas e xistos, ocorrendo em relevos de morros arredondados, apresentam moderada a alta capacidade de suporte à ocupação com sua suscetibilidade à erosão variando de baixa a alta (Foto 1), e rochas como quartizitos e formações ferríferas, ocorrendo principalmente em cristas de serras com pouca ou nenhuma cobertura; apresentam capacidade de suporte à ocupação elevada a muito elevada com baixa suscetibilidade a erosão (Foto 2) (PIMENTEL et al., 2005).

Sobre estas unidades, atuaram três eventos tectônicos que deformaram e arquitetaram o QF: o evento Rio das Velhas (2,9-2,68 Ga), com direção nordeste-sudoeste, o Transamazônico (2,1-1,9 Ga), com estruturas de vergência para noroeste, e o Brasiliano (0,7-0,45 Ga), com um movimento de massa de leste para oeste (CHEMALE et al., 1994).

Estes eventos, aliados à capacidade de resistências das rochas ao intemperismo, moldaram o relevo da área que Ross (1985) descreve, de maneira geral, como pertencente às regiões montanhosas dos Planaltos e Serras do Atlântico Leste Sudeste, sendo que no Quadrilátero Ferrífero está inserida, de acordo com Medina et al. (2005), na unidade morfológica do Vale Anticlinal do Rio das Velhas (VARV), representando uma zona deprimida, com uma morfoestrutura de anticlinal escavado com morros de topos alinhados (de orientação leste oeste), coincidindo com o sentido das dobras do Supergrupo Rio das Velhas, e vertentes retilíneas a côncavas, limitada pelo Platô do Sinclinal Moeda, a sul pelo Batólito de Itabirito e a leste pelos Patamares escalonados do Jaguará, como mostrado na Figura 2 (MEDINA et al., 2005).

A hidrografia encaixada nos vales do VARV apresenta uma alta densidade de drenagem com padrão em treliça e retangular, demonstrando forte controle estrutural (MEDINA et al., 2005). Entretanto, localmente foi observado que a área de estudo apresenta um comportamento dendrítico de drenagem.

Nova Lima está situada em contexto de bioma da Mata Atlântica típica de ambientes com relevo de altitudes e variações climáticas como as já descritas (IBGE, 2004). Dentro da área de estudo foram identificas, através de imagens de satélite, ortofotos e visitas técnicas, unidades como as matas e florestas fechadas, os campos, predominantemente em áreas com altitudes mais elevadas e solos rasos (Foto 3), as pastagens que aparecem, principalmente, ao longo do Rio das Velhas e o solo exposto, caracterizado por áreas desprovidas de cobertura vegetal, com possível exposição da rocha, 


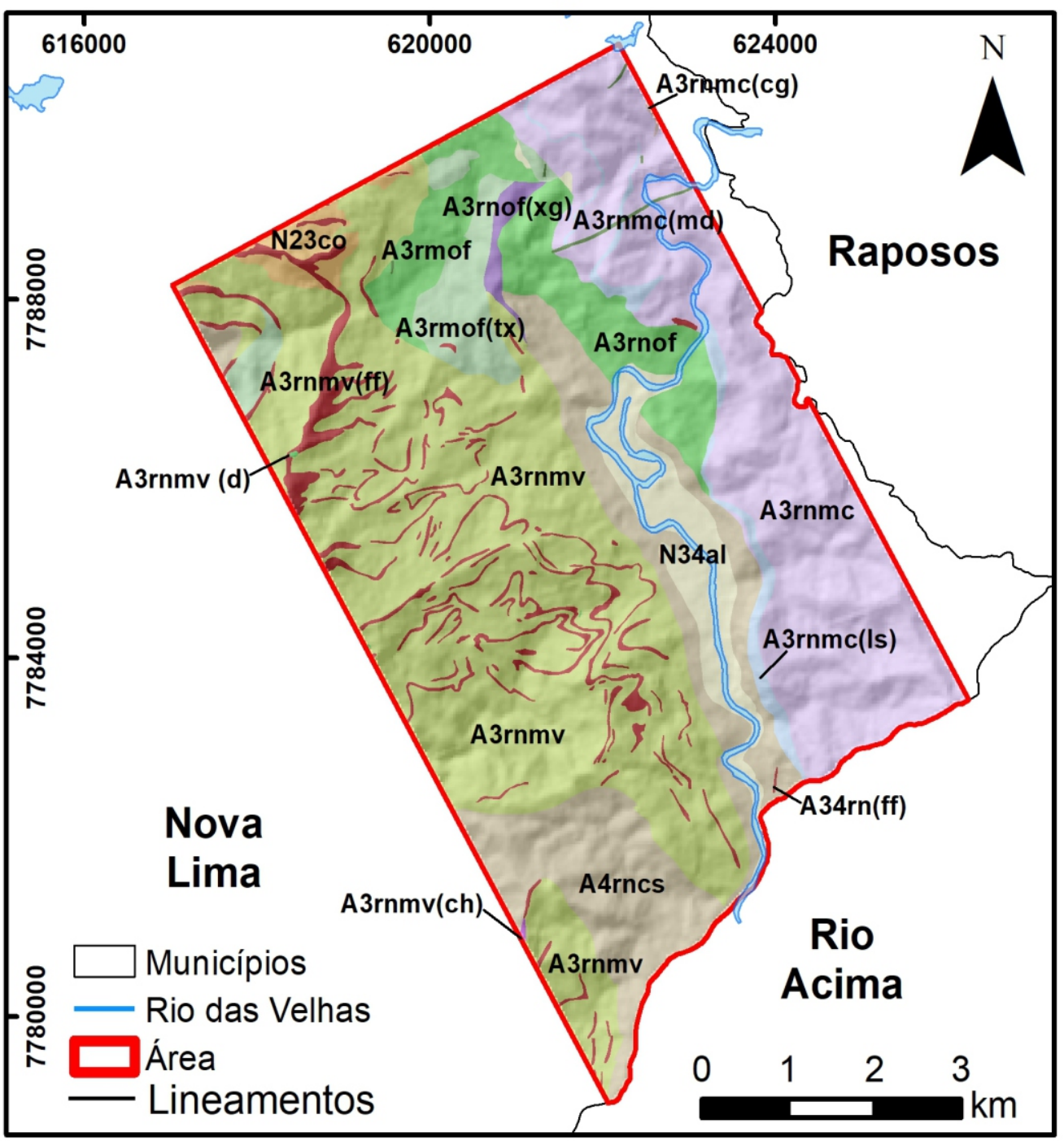

Fanerozoico

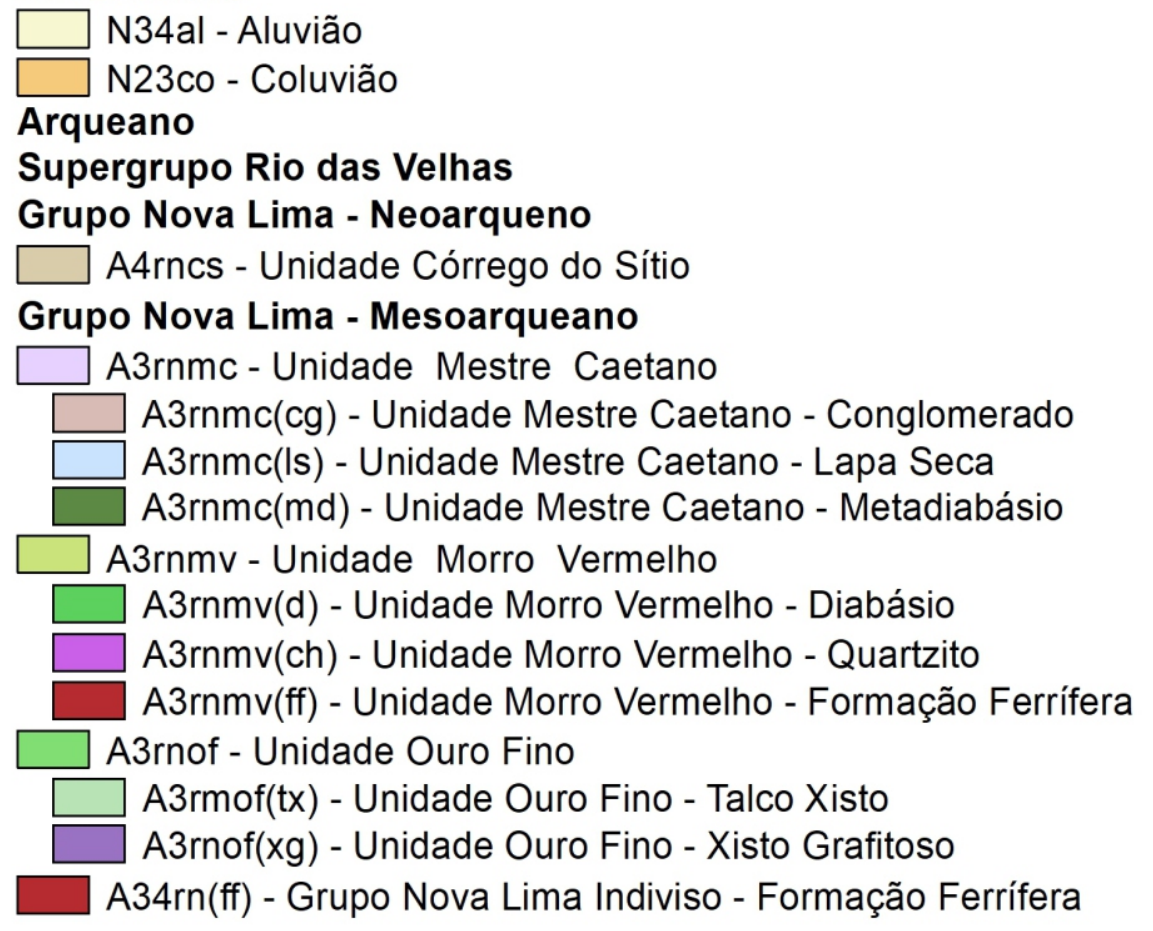




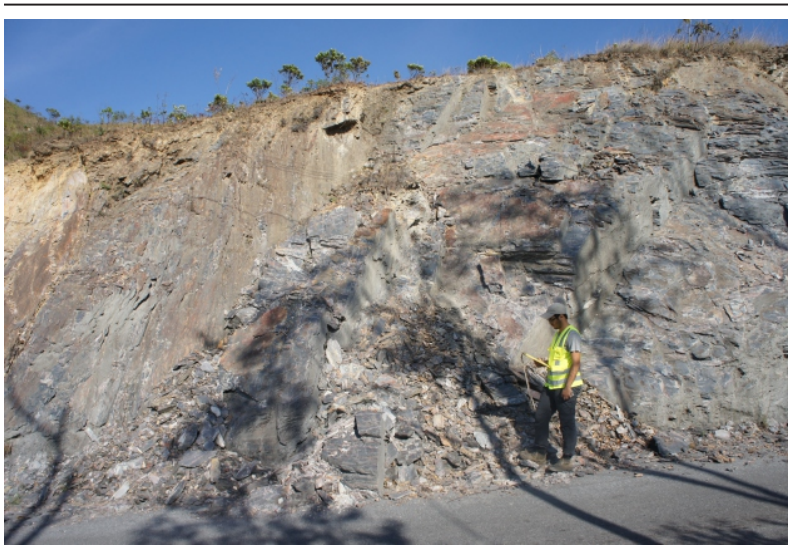

Foto 1 - Xistos com alta susceptibilidade a erosão, com desplacamento no sentido da foliação.

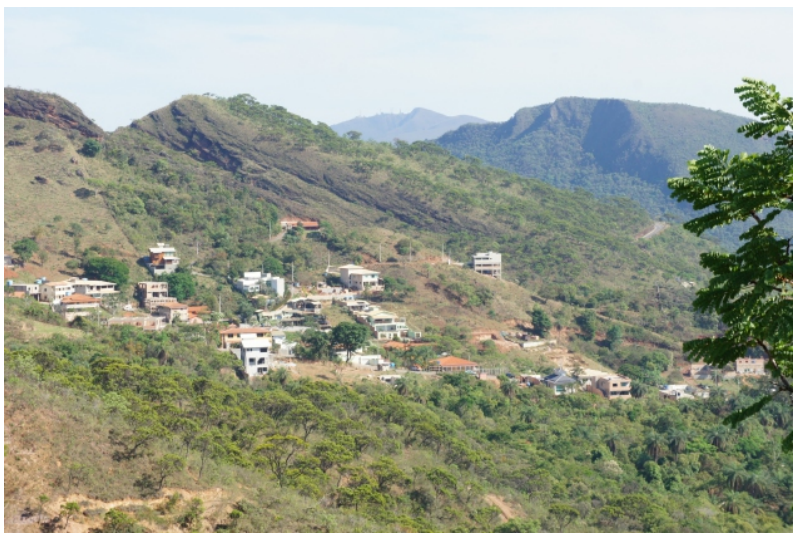

Foto 2-Litologia com baixa susceptibilidade a erosão.

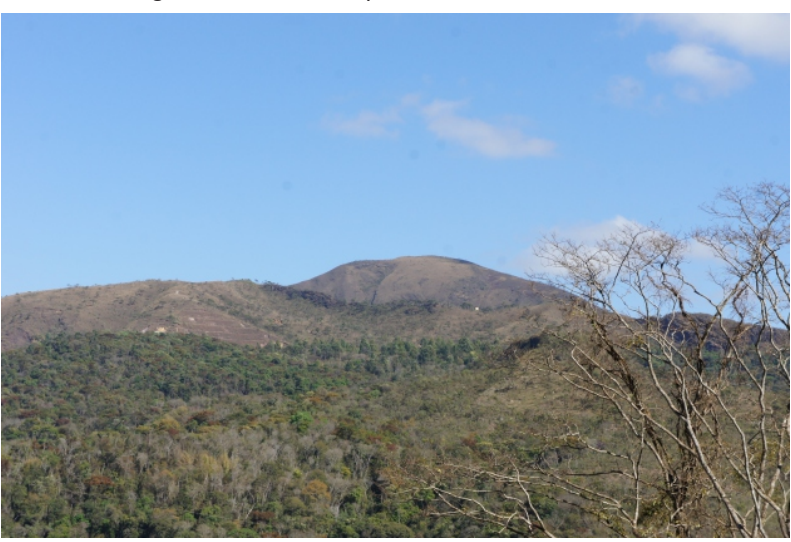

Foto 3 - Florestas fechadas na porção do vale e campos no topo de morro.

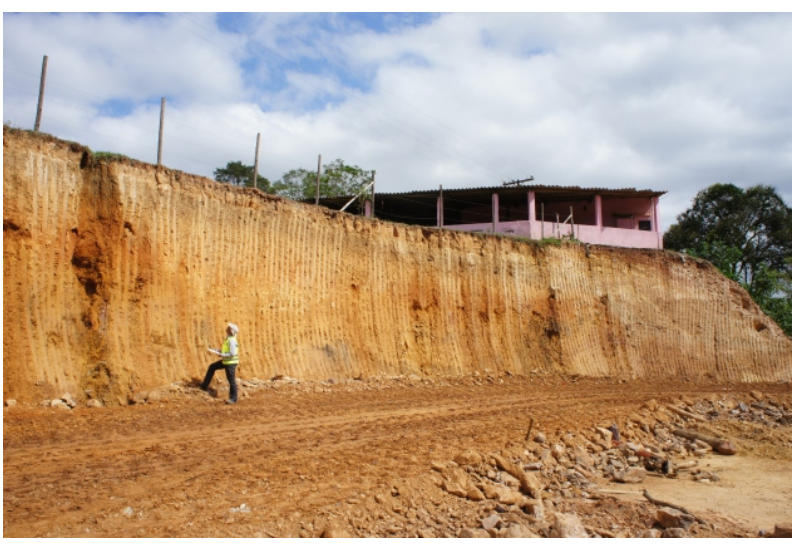

Foto 4 - Solo exposto, com processo de ravinamento, devido ao alto ângulo de corte.

além de áreas com processos erosivos como ravinamentos, deslizamentos e voçorocamento (Foto 4).

\section{MATERIALE MÉTODOS}

Para Moura (2007), a aplicação da metodologia de análise de multicritérios tem como característica principal a criação de análise de sínteses com objetivo de identificar áreas prioritárias para algum fenômeno ou arranjo geográfico. Para tal, Moura et al. (2011), descrevem que primeiramente deve se definir o que se pretende obter através da combinação de variáveis e, assim, selecionar temas de mapeamento e a estruturação de uma base de dados cartográfica e alfanumérica.

O segundo passo é trabalhar os dados coletados na forma de planos de informação que devem retratar a distribuição da variável em superfície (ib.id.). De acordo com estes mesmos autores, existe uma tendência a realizar as operações de modelos no formato raster (modelo em formatos matriciais). Isto se justifica pela relação de topologia implícita ao processo matricial que otimiza o cruzamento de dados, em alguns casos, indispensável para os modelos (MOURA, 2007).

A seleção da área de estudo se deu, primariamente, por observações feitas em campo, quando percebeu-se que na região ocorrem ocupações irregulares de áreas de encostas que estão sujeitas a eventos de movimentos de massa. Partindo disso, buscou-se delimitar uma zona em que há uma tendência de crescimento urbano e que há risco de ocorrência de movimentos de massa, para que o produto final possa servir como base de mapeamento geológico para fins de planejamento e gestão urbana. Partindo dessas observações, os núcleos urbanizados e o eixo da rodovia MG-030 foram considerados como zonas de indução ao crescimento urbano e, desta, foi considerado uma zona de $2 \mathrm{~km}$ e, daqueles, foi considerado um raio de $1 \mathrm{~km}$. Em ambos os casos essas áreas foram demarcadas com auxílio da ferramenta buffer disponível no software ArcGIS 10.3.

Definido o polígono que contempla a área de estudo, foram gerados mapas temáticos, a saber: litologia, solo, declividade, densidade de lineamentos estruturais, densidade de drenagem e de cobertura vegetal e ocupação do solo, utilizando o software ArcGIS 10.3, com intuito de observar as feições na área estudada e transformar estes dados em camadas para a síntese de multicritérios de pesos por evidências.

A base cartográfica para litologia foram as cartas geológicas de Itabirito e Belo Horizonte, na escala de 1:25.000, as quais foram vetorizadas pela Companhia de Desenvolvimento Econômico de Minas Gerais (CODEMIG) do mapeamento realizado por Dorr (1969). As unidades litológicas descritas na área de estudo foram agrupas com base na sua propriedade geotécnica descritas por Pimentel et al. (2005), como a capacidade de suporte e a suscetibilidade à erosão.

Os dados de Pedologia foram mapeados pelo Programa APASUL por Shinzato \& Filho (2005) em escala 1:50.000 e vetorizados para este trabalho e, na ausência de informação, foram levados em consideração os tipos de rochas. E depois agrupados nas classes de solo arenoso, 
silto-arenoso, siltoso e argiloso.

Já os dados de inclinação do relevo foram obtidos através da Imagem SRTM, pelo United States Geological Survey (USGS) (2017), com 30m de resolução espacial e calculadas em porcentagem através do software ArcGIS 10.3, utilizando as classes de declividade definidas pela Empresa Brasileira de Pesquisa Agropecuária (EMBRAPA) (1979), que são: 0 a 3\% plano, 3 a 8\% suave-ondulado, 8 a $20 \%$ ondulado, 20 a $45 \%$ forte-ondulado, 45 a $75 \%$ montanhoso e maior que $75 \%$ forte-montanhoso.

A cobertura vegetal foi vetorizada a partir da ortofoto da Companhia de Pesquisa de Recursos Minerais (CPRM) (2015), com $30 \mathrm{~cm}$ de resolução espacial e de forma complementar, a imagem Landsat-8 (OLI) disponibilizadas pelo Instituto Nacional de Pesquisas Espaciais (INPE) (2017), com 15m de resolução. Embora tenham diferentes escalas, esta é mais recente a ortofoto, possibilitando visualizar novas áreas de crescimento. Demarcou-se as zonas homólogas para as feições de área antropizada, solo exposto, floresta/mata e campo/pastagem.

Para a análise da influência da hidrografia sobre o fenômeno estudado, foi realizado o cálculo da densidade de drenagem por bacias hidrográficas. Para isso utilizaram-se os arquivos vetoriais da rede hidrográfica disponibilizada pela CPRM (2015). Realizou-se a delimitação das bacias hidrográficas a partir da modelagem hidrológica disponível no pacote de ferramentas de Análise Espacial do Software ArcGIS 10.3. O cálculo consiste na somatória do comprimento dos canais e na divisão deste resultado pela área de drenagem da bacia hidrográfica e é descrito por Tucci (2001).

A análise da influência da geologia estrutural sobre o fenômeno estudado foi realizada a partir do cálculo de densidade de lineamentos estruturais, calculados com auxílio da ferramenta de densidade de Kernel, presente no software ArcGIS 10.3. Por definição, a densidade de Kernel é o método estatístico probabilístico não paramétrico para interpolação de curvas de densidade (LANA, 2009).

Os lineamentos foram vetorizados a partir do dado de "relevo sombreado" gerado no mesmo software. A construção desse tipo de dado se justifica pelo fato de que os lineamentos devem ser considerados para uma análise do risco aos movimentos de massa, entretanto, é preciso que os dados sejam convertidos para o formato matricial. Nesse sentido, a criação da densidade de lineamentos permite que essa informação seja mesclada aos demais dados. $O$ resultado apresenta, em um arquivo raster, as áreas com maior concentração de lineamentos. É importante dizer que, neste trabalho, as informações coletadas estão em diferentes escalas e dessa maneira decidiu-se pela adoção de interação de dados no valor da célula (pixel) de $5 \mathrm{~m}$, buscando aprimorar a representação visual dos dados, entretanto deve-se considerar que a acurácia cartográfica do resultado está limitada à escala da fonte dos dados de entrada do modelo, o que responde pela escala de 1:50.000, considerando-se o dado menor escala.
As atividades de campo tiveram por objetivo principal observar as feições analisadas na etapa anterior in situ, observar os padrões de crescimento urbano, seu risco inerente e, sobretudo, validar os dados coletados.

Por fim procedeu-se à realização da análise de multicritérios utilizando o software ArcGIS 10.3. Para tal foi construída uma Árvore de Decisões (Tabela 1) que demonstra como foram combinadas as variáveis pelo processo de análise de multicritérios, sendo que os pesos e notas foram coletados utilizando a metodologia Delphi, descrita por Sousa (2017), contando com apoio de profissionais da Secretaria de Meio Ambiente de Nova Lima, professores do Centro Universitário de Belo Horizonte (UNIBH) e profissionais da geologia.

Sousa (2017) descreve em seu site que este método permite a indivíduos de um grupo lidarem com um problema complexo através da reunião de informações a partir da análise de especialistas, transformando um resultado qualitativo em quantitativo. No entanto, é necessário que cada especialista analise separadamente e sem o conhecimento de quem são os outros analistas, e domine o fenômeno retratado em cada camada de informação, assim como tenha conhecimento sobre o território em estudo (LINSTONE \& TUROFF, 2002; MOURA et al., 2011).

Com o intuito de elaborar a tabela de ponderadores (Tabela 1), foram inseridas as variáveis litologia, solo, inclinação do relevo, hidrografia, lineamentos e cobertura vegetal, que correspondem aos critérios de análise estabelecidos no presente trabalho, e trabalhadas na forma de mapas temáticos.

Cada variável tem vinculados à mesma os componentes de legenda que a compõe. Estes receberam notas de 0 a 10 sendo 0 os casos considerados como irrelevantes à formação de movimentos de massa e 10 aqueles considerados como muito relevantes na formação de movimentos de massa.

Tabela 1 - Árvore de decisões base para a síntese de ocorrência de movimentos gravitacionais. Pesos e Notas das análises Delphi.

\begin{tabular}{|c|c|c|c|c|}
\hline Variáveis & $\begin{array}{l}\text { Pesos } \\
\text { (\%) } \\
\text { autores }\end{array}$ & \multicolumn{2}{|c|}{ Descrição } & $\begin{array}{l}\text { Notas } \\
\text { autores }\end{array}$ \\
\hline \multirow{8}{*}{ Litologia } & \multirow{8}{*}{$25,0 \%$} & \multicolumn{2}{|c|}{ Depósitos aluviares } & 9,0 \\
\hline & & \multicolumn{2}{|c|}{ Unidade coluvionar } & 10,0 \\
\hline & & \multicolumn{2}{|c|}{ Quartizitos } & 1,0 \\
\hline & & \multicolumn{2}{|c|}{ Quartzitos e Xistos } & 5,0 \\
\hline & & \multicolumn{2}{|c|}{ Rochas Ultra Básicas } & 6,0 \\
\hline & & \multicolumn{2}{|c|}{ Itabiritos } & 2,0 \\
\hline & & \multicolumn{2}{|c|}{ Xistos } & 8,0 \\
\hline & & \multicolumn{2}{|c|}{ Xistos e Quartzitos Finos } & 7,0 \\
\hline \multirow{4}{*}{ Solo } & \multirow{4}{*}{$15,0 \%$} & \multicolumn{2}{|c|}{ Arenoso } & 10,0 \\
\hline & & \multicolumn{2}{|c|}{ Silto-arenoso } & 2,0 \\
\hline & & \multicolumn{2}{|c|}{ Siltoso } & 8,0 \\
\hline & & \multicolumn{2}{|c|}{ Argiloso } & 5,0 \\
\hline \multirow{6}{*}{$\begin{array}{l}\text { Inclinaçāo de } \\
\text { Relevo }\end{array}$} & \multirow{6}{*}{$25,0 \%$} & $0-3 \%$ & Plano & 0,0 \\
\hline & & $3-8 \%$ & Suave-ondulado & 2,0 \\
\hline & & $8-20 \%$ & Ondulado & 4,0 \\
\hline & & $20-45 \%$ & Forte-ondulado & 6,0 \\
\hline & & $45-75 \%$ & Montanhoso & 8,0 \\
\hline & & $>75 \%$ & Forte-montanhoso & 10,0 \\
\hline \multirow{3}{*}{ Hidrografia } & \multirow{3}{*}{$5,0 \%$} & \multicolumn{2}{|c|}{ Alta densidade de drenagens } & 8,0 \\
\hline & & \multicolumn{2}{|c|}{ Média densidade de drenagens } & 5,0 \\
\hline & & \multicolumn{2}{|c|}{ Baixa densidade de drenagens } & 2,0 \\
\hline \multirow{3}{*}{$\begin{array}{l}\text { Lineamentos } \\
\text { Estruturais }\end{array}$} & \multirow{3}{*}{$20,0 \%$} & \multicolumn{2}{|c|}{ Alta densidade de lineamentos } & 10,0 \\
\hline & & \multirow{2}{*}{\multicolumn{2}{|c|}{$\begin{array}{l}\text { Média densidade de lineamentos } \\
\text { Baixa densidade de lineamentos }\end{array}$}} & 8,0 \\
\hline & & & & 4,0 \\
\hline \multirow{4}{*}{$\begin{array}{l}\text { Cobertura Vegetal } \\
\text { e Uso do Solo }\end{array}$} & \multirow{4}{*}{$10,0 \%$} & \multicolumn{2}{|c|}{ Área antropizada } & 7,0 \\
\hline & & \multicolumn{2}{|c|}{ Solo Exposto } & 10,0 \\
\hline & & & Nativa & 1,0 \\
\hline & & & Pastagem & 4,0 \\
\hline
\end{tabular}


Estes dados foram convertidos para raster para possibilitar a integração dos dados. Todos os dados foram reclassificados conforme os pesos e notas atribuídas pela equipe de especialistas por meio do método de Delphi. Para a realização da síntese por multicritérios de peso por evidência, utilizou-se a calculadora raster disponível no software ArcGIS 10.3.

O procedimento faz a somatória das camadas multiplicado pelo seu ponderador em porcentagem, apresentados ordenadamente na árvore de decisões da Tabela 1 e apresentado pela Equação 1.

$$
\begin{gathered}
S M=v_{1} \times\left(\frac{p_{1}}{100}\right)+v_{n} \times\left(\frac{p_{n}}{100}\right) \\
\text { Equação 1: Onde SM }=\text { Síntese de } \\
\text { Multicritérios, } \mathrm{v}=\text { variável, } \mathrm{p}=\text { peso [\%]. }
\end{gathered}
$$

\section{RESULTADOS E DISCUSSÕES}

Conforme apresentado na metodologia, as camadas geradas (Figura 4) foram transformadas em superfícies potenciais de ocorrência do fenômeno estudado, segundo seu grau de pertinência e, posteriormente, foram combinadas através de uma análise de multicritérios, gerando um mapa de suscetibilidade ao risco à formação de movimentos gravitacionais de massa (Figura 5).

É possível observar, que as porções de maior risco concentram-se a leste e norte, onde os elementos de maior peso à ocorrência de movimentos de gravitacionais de massa são recorrentes.

A síntese demonstra claramente como a correlação entre as variáveis condiciona o risco analisado. Percebe-se que as litologias mais frágeis, como, por exemplo, os xistos e as rochas básicas, estão dispostas em quase toda a região (Figura 4A), o que por si só representa grau de risco médio-alto. Porém, quando analisamos esse dado associado a outros fatores, como uma alta concentração de lineamentos estruturais (Figura 4E), declividades elevadas (Figura 4C) e solos frágeis, podemos concluir que se trata de uma área com alto risco de ocorrência de movimentos gravitacionais de massa.

Pode-se destacar, também, a correlação entre os dados na porção sudeste da área de estudo. Mesmo a densidade de drenagens (Figura 4D) tendo recebido um baixo peso para a geração da síntese de multicritérios, observa-se nessa área que a somatória dos fatores levou a um elevado risco de ocorrência dos movimentos gravitacionais de massa, como solo arenoso, alta declividade, presença de xistos e quartzitos finos e baixa cobertura vegetal.

É importante considerar, também, que as áreas antropizadas e as áreas de solo exposto foram consideradas, pela equipe consultada, como fatores indutores do risco estudado. Dessa maneira, o resultado apresenta grandes áreas urbanizadas que estão situadas sobre locais de alto risco a ocorrência de movimentos de massa. Nesses locais as ocupações já ocorrem sobre locais em que há a presença de solos argilosos, médiaalta declividade, média-alta concentração de lineamentos estruturais, média densidade de drenagem e presença de xistos. São consideradas, portanto, zonas críticas encontradas no estudo, em que o poder público deve intervir rapidamente para prevenir perdas materiais e vitais.

$O$ resultado nos auxilia, ainda, a entender as zonas de menor risco à ocupação antrópica, ou seja, que possuem menor suscetibilidade a ocorrência de movimentos de massa. É importante que o poder público considere esses locais como favoráveis à indução do crescimento urbano e na autorização da abertura de novos loteamentos e com isso se precavendo de problemas futuros como despesas emergenciais (obras de contenção, por exemplo) e remoção de pessoas.

A partir da síntese apresentada na Figura 5 é possível quantificar as áreas de riscos. Tal análise foi realizada tanto para toda a área de estudo quanto para a área urbanizada e está expresso na Tabela 2. Observa-se que, em ambas as análises, predominam as classes de médio a alto risco, porém nas áreas urbanizadas há uma maior proporção de áreas de alto risco em detrimento das de baixo risco, o que corrobora a afirmação de necessidade de intervenção por parte do poder público.

\section{CONCLUSÕES E RECOMENDAÇÕES}

A análise de multicritérios mostrou-se uma ferramenta muito válida para análise em múltiplas camadas, no caso deste trabalho, apresentando zonas com maior potencial a ocorrência de movimentos gravitacionais.

Mostra, também, a importância da geologia para a gestão de riscos em um ambiente urbano. Uma vez que o risco inerente ao ambiente físico está vinculado à complexidade dos componentes geológicos, e a ação humana sobre ele pode criar ou ampliar problemas geoambientais, como movimentos gravitacionais, causadores de danos físicos e/ou matérias.

A utilização do método Delphi, apesar de apresentar resultados satisfatórios, deve ser realizada com cautela, uma vez que o método requer muita atenção aos valores que serão pontuados. O método traz em seu conceito premissas como a coletivização das responsabilidades, o que permite que vários profissionais analisem as variáveis envolvidas no fenômeno. Essa prática é muito relevante, pois tende a tornar os resultados mais assertivos do que na individualização a análise. Entretanto, é sempre importante salientar de que toda análise de síntese representa a caracterização de um fenômeno baseado em variáveis e premissas preestabelecidas pela equipe envolvida no projeto. Além disso, possui espacialidade e temporalidade definida.

A produção do material cartográfico também se mostrou importante no presente trabalho, já que a mesoestruturas e megaestruturas deveriam se instalar pensando nas condições de suporte do sistema geológico (infraestrutura), devido à complexidade dos componentes geológicos e geomorfológicos. Esse tipo de material produzido pode auxiliar os gestores públicos e privados no processo de planejamento territorial e na tomada de decisões a curto e longo prazo, apontando 
áreas de suscetibilidade e/ou vulnerabilidade, mostrando onde devem ser feitas as intervenções necessárias na paisagem a fim de garantir uma boa interação entre o ambiente físico e a expansão urbana.

Para além dos movimentos de massa, este tipo de análise pode ser aplicada para compreensão de outros fenômenos como risco a inundação, conflitos ambientais na ocupação urbana, regiões com maior potencial de crescimento urbano, dentre outros. Nesses casos, outras variáveis podem ser consideradas e ponderadas para geração de diferentes tipos produtos.

\section{AGRADECIMENTOS}

Agradecemos ao Ricardo Augusto Custódio, Geólogo da CODEMIG pelo apoio geológico, à secretaria de Meio Ambiente de Nova Lima, pelo auxílio e fornecimento de dados. Aos profissionais que contribuíram analisando nossa tabela de ponderadores. $\mathrm{E}$ a todos aqueles que de alguma maneira nos ajudaram na elaboração deste estudo.

Tabela 2 - Análise estatísticas das categorias de risco para a síntese Delphi.

\begin{tabular}{|c|c|c|c|c|}
\hline \multirow[b]{2}{*}{ Autores } & \multicolumn{2}{|c|}{$\begin{array}{c}\text { Área Total } \\
\left(52 \mathrm{~km}^{2}\right)\end{array}$} & \multicolumn{2}{|c|}{$\begin{array}{c}\text { Área } \\
\text { urbanizada } \\
\left(11 \mathrm{~km}^{2}\right)\end{array}$} \\
\hline & $\mathrm{Km}^{2}$ & $\%$ & $\mathrm{Km}^{2}$ & $\%$ \\
\hline Baixo & 12 & 23 & 1 & 11 \\
\hline Médio & 25 & 48 & 6 & 52 \\
\hline Alto & 15 & 29 & 4 & 37 \\
\hline
\end{tabular}

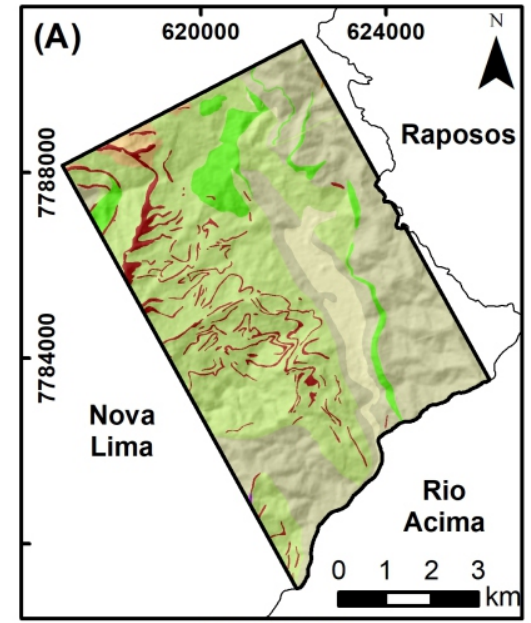

LITOLOGIA

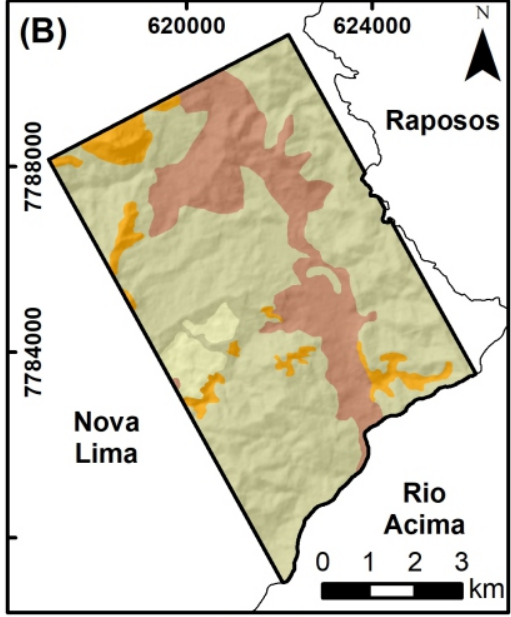

SOLOS

Silto arenoso Siltoso

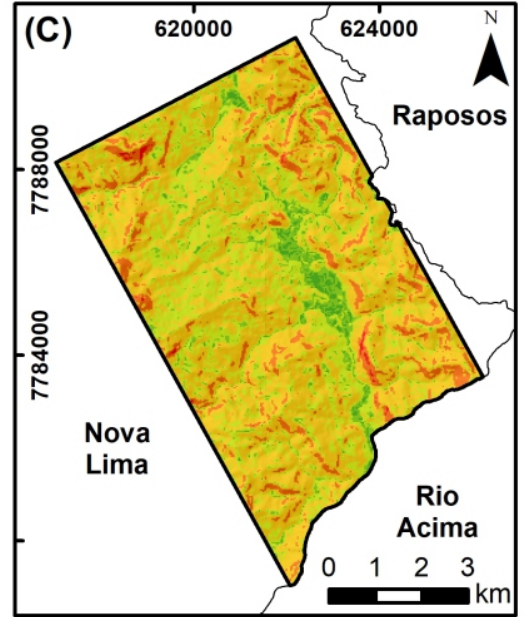

DECLIVIDADE (\%)

0 - $3 \square 8-20 \square 45-75$

$3-8 \square 20-45 \square>75$ Unidade Coluvionar $\square$ Xisto
Quartizitos e xistos $\square$ Básica - Ultra Básica Quartzito Itabiritos

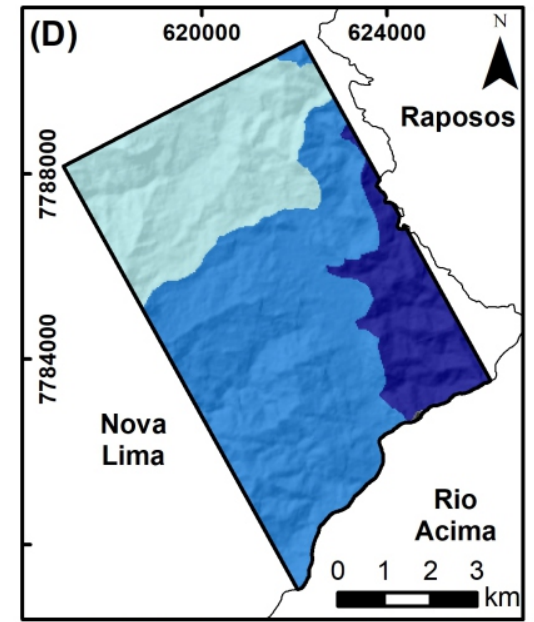

DENSIDADE DE DRENAGEM $\square$ Baixa $\square$ Média $\square$ Alta

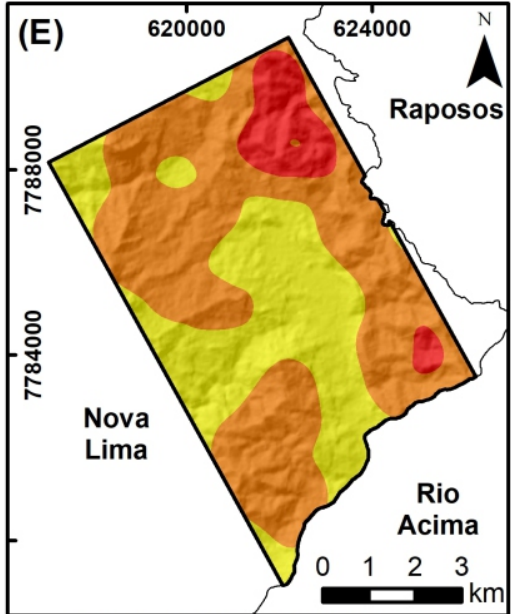

DENSIDADE DE LINEAMENTOS $\square$ Baixa $\square$ Média Alta

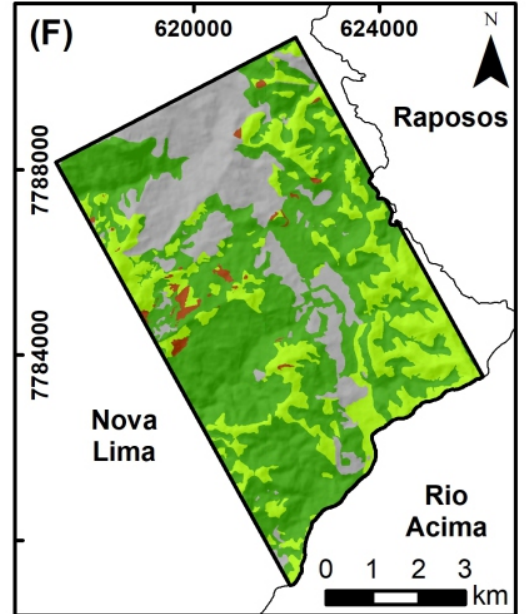

COBERTURA VEGETAL E USO DO SOLO

Área antropizada $\square$ Floresta / mata Solo exposto
Campo / pastagem

Figura 4 - Mapas temáticos utilizados na síntese de camadas. 4(A) Mapa de litológico com dados de geotecnia; 4(B) Mapas de solos; 4(C) Mapa de declividade em porcentagem; 4(D) Mapa de densidade de drenagem; 4(E) Mapa de densidade de lineamentos; 4(F) Mapa de cobertura vegetal e uso do solo. 


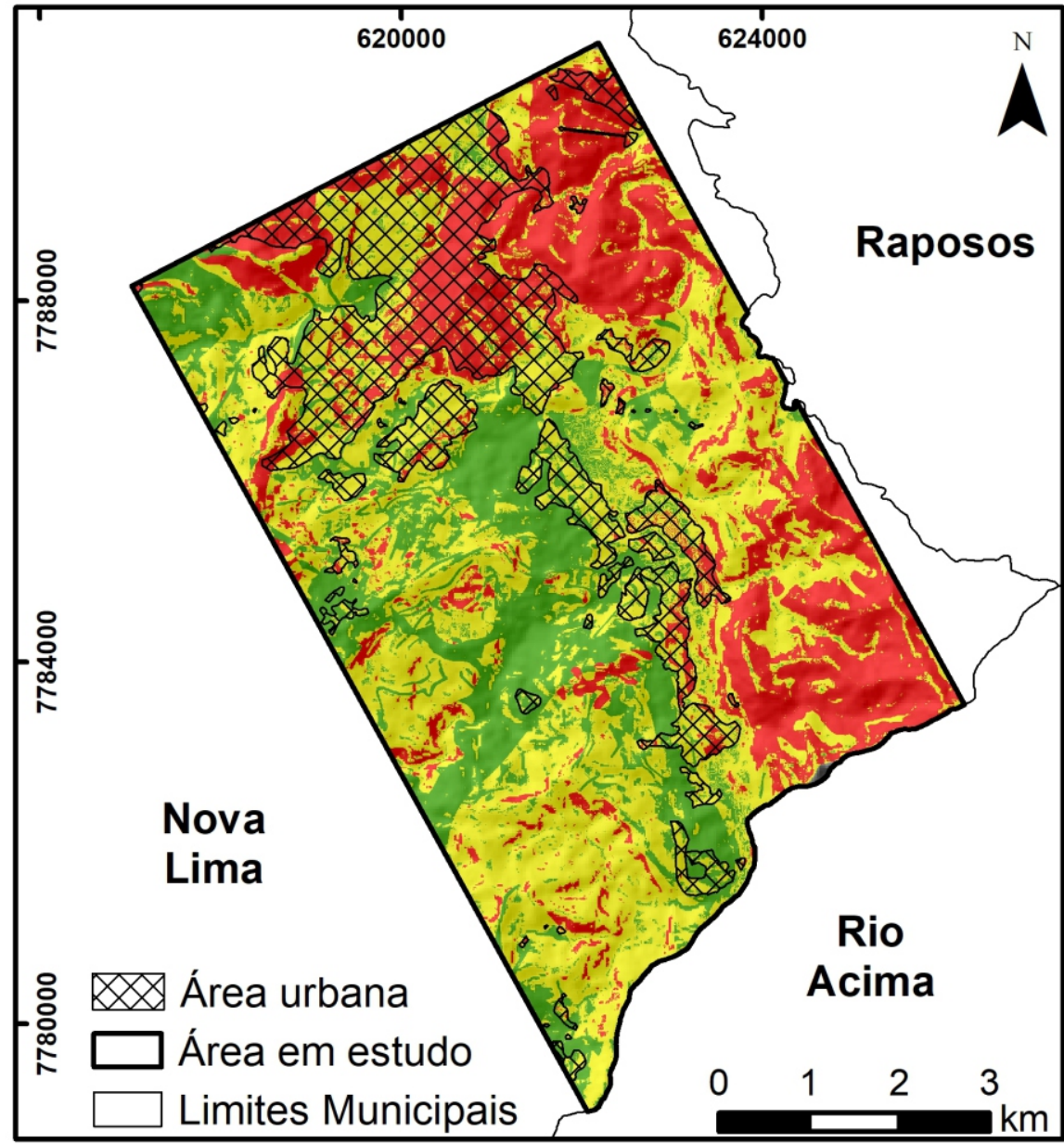
Baixo $(1,75-4,59)$
Médio $(4,59-5,59)$
Alto $(5,59-8,62)$
RISCO À MOVIMENTOS GRAVITACIONAIS E DE MASSA

Figura 5-Mapa Síntese.

\section{REFERÊNCIAS BIBLIOGRÁFICAS}

ALKMIM, F. F.; MARSHAK, S. 1998. Transamazonian Orogeny in the Souther São Francicos Craton Region, Minas Gerais, Brazil: evidence for Paleoproterozoic collision and collapse in the Quadrilátero Ferrífero. Precambrian Research. 1998, p. 29-58.

CÂMARA, G.; DAVIS, C.; MONTEIRO, A. M. V. 2001. Introdução à Ciência da Geoinformação. Instituto Nacional de Pesquisas Espaciais - INPE. São José dos Campos. 2001. p. 344.

CARVALHO, E. T. 2001. Geologia Urbana para todos - Uma visão de Belo Horizonte. 2a Edição. Belo Horizonte: s.n., 2001. p. 176.

CERRI, L. E. S.; AMARAL, C. 1998. Riscos Geológicos. Geologia de Engenharia. São Paulo, ABGE (Associação Brasileira de Geologia de Engenharia). 1998. p. 301310.
CHEMALE, F. Jr.; ROSIÈRE, C. A.; ENDO, I. 1994. The Tectonic Evolution of the Quadrilátero Ferrífero, Minas Gerais. Um modelo. Precambrian Research. 1994, p. 2554.

Climate Data. 2017. Clima - Nova Lima. Climate-Data.org. 2017. Acessado em: 07/09/2017. Disponível em: https://pt.climate-data.org/location/24940/

COWEN, D. J. 1988. GIS versus CAD versus DBMS: what are the differences. 1988, Vol. 54, p. 1551-1554.

CPRM - Companhia de Pesquisa de Recursos Minerais. 2015. Cartas de Suscetibilidade a Movimentos Gravitacionais de Massa e Inundações. Portal CPRM. 2015. Shapes de estradas e hidrografia; Ortofotos com $30 \mathrm{~cm}$ de resolução - Município de Nova Lima.Acesso em: 20/08/17. Disponível em: http://www.cprm.gov.br/publique/GestaoTerritorial/Geologia-de-Engenharia-e-RiscosGeologicos/Cartas-de-Suscetibilidade-aMovimentos-Gravitacionais-de-Massa-eInundacoes-3507.html. 
CULSHAW, M. G.; PRICE, S. J. 2013. A Contribuição da Geologia Urbana ao Desenvolvimento, Recuperação e Conservação de Cidades [ed.] K. Canil e F. N. de Jorge. [trad.] G. M. Garda. 1a Edição. São Paulo: ABGE - Associação Brasileira de Geologia e Engenharia e Ambiental, 2013. p. 148.

DA SILVA, J. X. 1999. Geoprocessamento para Análise Ambiental. Rio de Janeiro: Lageop, (apostila do Curso de Especialização em Geoprocessamento - Midia CDrom).,1999. p. 15.

DORR, J. V. N. Physiographic, Stratigraphic and Structural Development of the Quadrilátero Ferrífero Minas Gerais, Brazil - Regional Geology of the Quadrilátero Ferrífero, Minas Gerais, Brazil - DNPM / USGS. Washington, 1969.

EMBRAPA - EMPRESA BRASILEIRA DE PESQUISA AGROPECUÁRIA. 1979. Serviço Nacional de Levantamento e Conservação de Solos. Súmula da 10a Reunião Técnica de Levantamento de Solos. Rio de Janeiro: s.n., 1979. p. 83.

GOMES, M. A. F.; PEREIRA, L. C. 2014. Aspectos Geoambientais e Áreas Frágeis no Brasil. Revista Intellectus, $n^{\circ} 26$, Vol. 1. 2014. p. 5-19.

IBGE - Instituto Brasileiro de Geografia Estatística. 2004. Mapa de Biomas do Brasil. IBGE, MMA. 2004. Escala 1:5.000.000. Acesso em: 07/09/2017. Disponível em: http://institutopristino.org.br/atlas/

INPE - Instituto Nacional de Pesquisas Espaciais. 2017. INPE - Image Catalog. id: LO82180742017216CUB00, 2017. Imagens Landsat 8 , com $15 \mathrm{~m}$ de resolução. Acesso em: 07/07/2017.

Disponível em: http://www.dgi.inpe.br/CDSR/.

KELLER, E. A. 2011. Introduction to Enviromental Geology 5th ed. Pearson, 2011. p. 801.

LANA, R. M. 2009. Um pouco sobre Kernel. TerraLab, Universidade Federal de Ouro Preto, 2009. Disponível em:

LEGGET, R. F., 1969. Urban Geology. Canadian Building Digest, CBD - 113, National Research Council Canada. /Division of Building Research. Acessado em: 10/09/17. Disponível em: https://nparc.nrccnrc.gc.ca/eng/view/object/?id=9814d874-a1444aa2-a3f8-c72b1f79b138

LEGGET, R. F. 1973. Cities and Geology. Earth \& Planetary Science series. 1st ed. McGraw-Hill Book Company, 1973. p. 592.

LINSTONE, H. A., TUROFF, M. 2002. The Delphi Method Techniques and Applications. University of Southern California. 2002.
LOBATO, L. M. 2005. Projeto Quadrilátero Ferrífero Integração e Correção Cartográfica em SIG. Universidade Federal de Minas Gerais. Belo Horizonte, 2005.

MEDINA, A. I. M., DANTAS, M. E. e SAADI, A. 2005. Geomorfologia. Projeto APASUL RMBH - Estudos do Meio Físico - Geomorfologia. Belo Horizonte: CPRM, 2005, Vol. 6, p. 60. Escala 1:50.000. acional de Pesquisas Espaciais. Curitiba. Em: Anais XV Simpósio Brasileiro de Sensoriamento Remoto - SBSR, 2011. p. 690-697.

MOURA, A. C. M. 2007. Reflexões metodológicas como subsídios para estudos ambientais baseados em Análise de Multicritérios. Instituto Nacional de Pesquisas Espaciais. Florianópolis. Em: Anais do XIII Simpósio de Sensoriamento Remoto (SBSR), 2007. p. 2899-2906.

MOURA, A. C. M.; MAGALHÃES, D. M.; PARIZZI, M. G. 2011. Vocações e Conflitos de Interesse na Ocupação do Território da Região Metropolitana de Belo Horizonte - Apoio ao Plano Diretor de Desenvolvimento Integrado - PDDI. Instituto Nacional de Pesquisas Espaciais. Curitiba. Em: Anais XV Simpósio Brasileiro de Sensoriamento Remoto - SBSR, 2011. p. 690-697.

PARIZI, M. G. 2014. Desastres Naturais e Induzidos e o Risco Urbano. Rev

PIMENTEL, J., TEIXEIRA, C. Z. e SILVA, F. M. 2005. Geotecnia. Projeto APASUL RMBH - Estudos do Meio Físico - Geotecnia. Belo Horizonte: CPRM, 2005, Vol. 4, p. 111. Escala 1:50.000.

PNL, Prefeitura de Nova Lima. 2020. A História da Cidade. Acessado em: 06/04/2020. Disponível em: http://www.novalima.mg.gov.br/historia-da-cidade

ROCHA, N. A.; MOURA, A. C. M.; CASAGRANDE, P. 2018. Análise Combinatória e Pesos de Evidência na produção de Análise de Multicritérios em modelos de avaliação. GeoSIG (Revista Geografía y Sistemas de Información Geográfica). Luján, Año 10, Número especial, 2018, Sección I: Artículos. p. 49-74.

ROSS, J. L. S. 1985. Relevo brasileiro: uma nova proposta declassificação. $n^{\circ}$ 4, São Paulo: Revista do Departamento de Geografia, 1985, p. 25-39.

SHINZATO, E; FILHO, A. C. 2005. Geotecnia. Projeto APASUL RMBH - Estudos do Meio Físico - Pedologia. Belo Horizonte: CPRM, 2005, Vol. 5 parte A, p. 111. Escala 1:50.000.

SOUSA, A. B. Método Delphi. Consultado em 2017. Acesso em: 07/09/2017. Disponível em:https://sites.google.com/site/albertobarrossous a/metodologias-de-educacao/metodo-delphi ista Geonomos, n²2, Vol. 1. 2014. p. 1-9. 
SOUZA, L. A. 2004. Diagnóstico do Meio Físico como Contribuição ao Ordenamento Territorial do Município de Mariana (MG). Dissertação de Mestrado Departamento de Engenharia Civil, UFOP. Ouro Preto: s.n., 2004. p. 182.

TEIXEIRA, A.; MATIAS, A.; NOAL, L.F.; MORETTI, E. 1995. Qual a Melhor Definição de Sig. Ano 3, n 11, s.l.: Fator GIS, 1995, p. 20-24.

TUCCI. C. E. M. Hidrologia Ciência e Aplicação. 2a Edição 2001. Editora UFRGS. UFRGS, Rio Grande do Sul 2001. p. 943.

UNESP - Universidade Estadual Paulista. 2017. Conceitos de Geologia Ambiental. Rio Claro, São Paulo: IGCEUNESP, 2017. p. 10. Acessado em: 07/09/2017. $\begin{array}{llllllllll} & i & s & p & o & n & i & v & \text { e } & \text { । }\end{array}$ em:http://www.rc.unesp.br/igce/aplicada/ead/intro ducao/introd02.html

USGS - United States Geological Survey. 2017. Earth Explorer - Imagens SRTM. Resolução de $30 \mathrm{~m}$. Acessado em: 20/08/2017. Disponível em: https://earthexplorer.usgs.gov/.

XAVIER-DA-SILVA, Jorge. Geoprocessamento para análise ambiental. 1999. Rio de Janeiro: Lageop, 1999. 15 p. (apostila do Curso de Especialização em Geoprocessamento Midia CDrom).

ZAMBON, K.L et al. 2005. Análise de decisão multicritério na localização de usinas termoelétricas utilizando SIG. Pesqui. Oper. Rio de Janeiro, 2005. v. 25, n. 2, p. 183199. 